\title{
Study and Optimisation of Process Parameter in Turning Of EN 45 - Spring Steel Material Under Dry And MQL Conditions
}

\author{
Kosaraju Satynarayana ${ }^{1, *}$, Kumkuma Rajkiran $^{2}$, and Kalemula Sai Kiran ${ }^{2}$ \\ ${ }^{1}$ Assoc.Professor, GRIET, Mechanical Engineering Department, Hyderabad, India. \\ ${ }^{2}$ PG Student, GRIET, Mechanical Engineering Department, Hyderabad, India.
}

\begin{abstract}
Minimum quality lubrication has shown a noticeable changes with machining outcomes. MQL is one of updated technologies that have been prevailing in contributions towards production and environment enhancement. Present papers deals with the turning of EN 45 steel material which is commonly known to be spring material. En 45 one of the magnetic steel material with low manganese and high amount of carbons is turned under dry and MQL condition. DOE has been prepared with L9 taguchi. Machining factors of speed $(75,100,125 \mathrm{~m} / \mathrm{min})$, feed $(0.1,0.2,0.3 \mathrm{~mm} / \mathrm{rev})$ and depth of cut $(0.3,0.6,0.9 \mathrm{~mm})$. The surface roughness were optimized by considering the machining parameters of speed, feed, and depth of cut. For both the condition dry and MQL it was observed that speed at $125 \mathrm{~m} / \mathrm{min}$, feed at 0.1 and depth of cut at $0.3 \mathrm{~mm}$ was found optimum condition. The regression equation and mathematical model was generated using the experimental data. Furthermore the ANOVA analysis was performed and observed that in case of dry turning speed found to be most influencing parameter and in case of MQL turning Feed was found to be most influencing parameter.
\end{abstract}

\section{Introduction.}

EN45 is a manganese steel IS inbuilt spring action with medium spring content in it. Amount of manganese in it states the amount of retraction of forces after smaller deformations. EN45 is generally used in the leaf springs and coiled strings in automobiles and all the spring action required areas. Heat treatment is one of main noticeable factor while machining or processing of EN 45 steel. In order of processing it or while machining, industries perform a good lubricating effects to decrease the heat evolution while processing it. In order to maintain heat effect zone, flood lubrication is used. But as of the environmental aspects, present papers deals with machining it under minimum quantity lubrication effects. Lathe turning operation produces cutting force which are then categorized three components. They are thrust force $(\mathrm{Fz})$, feed forces $(\mathrm{Fx})$ and radial forces (Fy), out of which cutting force $(\mathrm{Fx})$ is taken under consideration as main forces while machining.

Minimum lubrication or micro-lubrication is one of the updated processes of the lubrication system that is being followed as the latest improvement in the production sectors. MQL elucidates the process of flow of lubrication mixed with air under high pressure [1]. The flow rate ranges from $5 \mathrm{ml} / \mathrm{hr}$ to $500 \mathrm{ml} / \mathrm{hr}$ and the flow pressure from 2 bar to 8 bar pressure [2]. Pressure, flow rate, distance from the shearing zone and nozzle diameter plays a vital role in MQL lubrication systems. By this practice the machining environment can be eliminated from oil contaminants, slippery and toxic work environments. Disposal of lubricants and coolants is one of the major and highly economical tasks which shows major variations in machining and maintenance costs [3]. In usage of MQL about $80 \%$ coolants usage can be eliminated and thereby reducing the environmental damage and working environments. MQL finds the solution for the global restrictions orders of lubrication disposable acts and regulations [4]. MQL Lubrication system provides good lubricating effect [5] and thereby increases the tool life and reduces the surface roughness [6].Whereas the flood lubrication also does the same with combining effect of layer formation on metal and increases the oxidizing effect on the surface when machined under water soluble and water flood cooling system. MQL (Minimum Quantity Lubrication) method has been developed as an alternative to flood cooling. In recent years, numerous studies on the usage of MQL in the machining of hard-to-machine materials have been performed

In previous study [7] taguchi method in design on tool wear with determine the machining parameters. The parameters selected were speed, feed rate and type of tool material while machining titanium alloy. Machining was performed under different lubrication effects and found that the minimum quantity lubrication has shown more optimum result when comparing them to dry and flood lubrication systems. Optimization was performed by ANOVA approach and stated that cutting speed has more influence on tool wear and surface roughness [9]. Rafeeq 
et al [8] experiments and states that depth and feed rate were considerable parameters for optimization of forces while machining EN 31 graded material. Authors have used Taguchi's orthogonal array principle in their research process. Nose radius is also one of the main factor in developing lesser cutting forces. Form the previous study, present paper deals with the experiments of turning on EN 45 over precision lathe coated inserts. Taguchi analysis is performed for the outcomes of surface roughness. Furthermore, the process is proceeded with generation of mathematical model based on the data obtained from the experiment. In addition, analysis of variance (ANOVA) has been performed to know the most contributing factor effecting the surface roughness.

\section{Experimentation process}

Commercially available EN 45 was procured from the market. Material is then made for chemical analysis to conform to standards of chemical composition. Chemical analysis is made and tabulate in table 1 as per the weight ratio. Commercially available petro-based MQL fluid was used in the experimentation. MQL physical and chemical properties was shown in table 2 .

Table 1. Chemical composition of EN45

\begin{tabular}{|l|l|l|l|l|l|}
\hline Elements & $\mathrm{C}$ & $\mathrm{Si}$ & $\mathrm{S}$ & $\mathrm{Mn}$ & $\mathrm{P}$ \\
\hline $\mathrm{Wt}(\%)$ & 0.559 & 1.805 & 0.009 & 0.875 & 0.019 \\
\hline
\end{tabular}

Table 2. Physical and chemical properties of MQL fluid

\begin{tabular}{|l|l|l|}
\hline Properties & $\begin{array}{l}\text { Units } \\
\text { (Methods) }\end{array}$ & $\begin{array}{l}\text { Strub Vulcan Futura } \\
\text { CF10 90405 }\end{array}$ \\
\hline $\begin{array}{l}\text { Appearance } \\
\text { (Concentrate) }\end{array}$ & Visual & Amber \\
\hline $\begin{array}{l}\text { Specific Gravity at } \\
\text { Room Temp }\end{array}$ & $\begin{array}{l}\text { ASTM D } \\
1298\end{array}$ & $0.84-0.86$ \\
\hline $\begin{array}{l}\text { Kinematic } \\
\text { Viscosity }\end{array}$ & $\begin{array}{l}\text { D-445 } \\
\left(\mathrm{eST}, 40^{\circ} \mathrm{C}\right)\end{array}$ & $9-12$ \\
\hline $\begin{array}{l}\text { Flash Point } \\
\text { (COC)Min }\end{array}$ & D-92(oc) & 130 \\
\hline
\end{tabular}

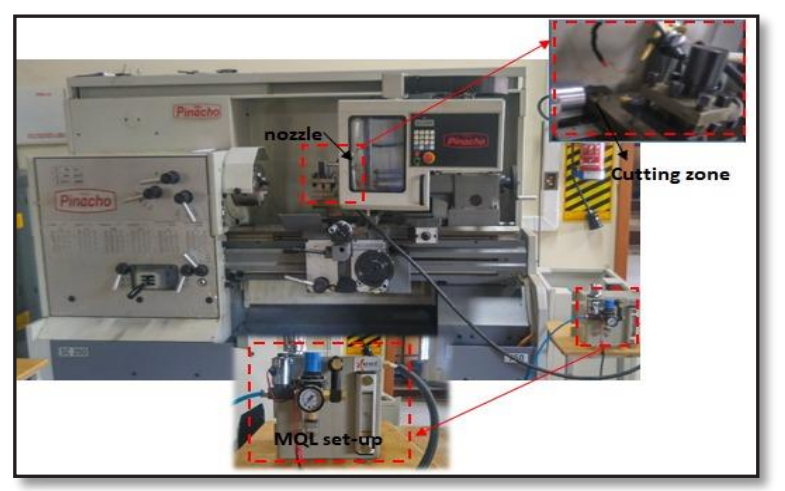

Fig.1. Experimental set-up

Simple turning operation was performed on $40 \mathrm{~mm}$ dia and $30 \mathrm{~mm}$ length bar with uncoated tool on the precision lathe set-up shown in Figure 1 in both dry and MQL conditions. As per the machining parameters shown in Table 3. Flow of MQL is controlled using a nozzle and flow has been regulated to be at a pressure of $60 \mathrm{ml} / \mathrm{hr}$ at pneumatic pressure of around $63 \mathrm{MPa}$. Nozzle is set to flow the fluid on the tool near to shear zone and travel along with the cutting line.

Table 3. Machining parameters.

\begin{tabular}{|l|l|c|c|c|}
\hline \multirow{2}{*}{ Parameters } & \multirow{2}{*}{$\begin{array}{c}\text { Notations } \\
\text { (units) }\end{array}$} & \multicolumn{3}{|c|}{ levels } \\
\cline { 3 - 5 } & v (m/min) & 75 & 2 & 3 \\
\hline Speed & $\mathrm{f}(\mathrm{mm} / \mathrm{rev})$ & 0.1 & 0.2 & 0.3 \\
\hline Feed & $\mathrm{d}(\mathrm{mm})$ & 0.3 & 0.6 & 0.9 \\
\hline Depth of cut &
\end{tabular}

Table 4. L9 orthogonal array and results of surface roughness

\begin{tabular}{|c|c|c|c|c|c|c|c|}
\hline \multirow{3}{*}{$\exp$} & \multirow{2}{*}{\multicolumn{3}{|c|}{$\begin{array}{l}\text { Machining } \\
\text { parameters }\end{array}$}} & \multicolumn{2}{|c|}{$\begin{array}{l}\text { Experimental } \\
\text { results }\end{array}$} & \multicolumn{2}{|c|}{ S/N Ratio } \\
\hline & & & & \multirow{2}{*}{$\begin{array}{c}\text { Dry } \\
\mathrm{Ra} \\
(\mu \mathrm{m})\end{array}$} & \multirow{2}{*}{$\begin{array}{c}\mathrm{MQL} \\
\mathrm{Ra} \\
(\mu \mathrm{m})\end{array}$} & \multirow{2}{*}{$\begin{array}{c}\text { Dry } \\
\mathrm{Ra} \\
(\mu \mathrm{m})\end{array}$} & \multirow{2}{*}{$\begin{array}{c}\mathrm{MQL} \\
\mathrm{Ra} \\
(\mu \mathrm{m})\end{array}$} \\
\hline & $v$ & $f$ & $d$ & & & & \\
\hline 1 & 1 & 1 & 1 & 1.03 & 0.657 & -0.256 & 3.648 \\
\hline 2 & 1 & 2 & 2 & 2.427 & 2.101 & -7.701 & -6.44 \\
\hline 3 & 1 & 3 & 3 & 3.625 & 3.49 & -11.18 & -10.85 \\
\hline 4 & 2 & 1 & 2 & 1.05 & 0.582 & -0.423 & 4.7015 \\
\hline 5 & 2 & 2 & 3 & 2.482 & 2.078 & -7.896 & -6.352 \\
\hline 6 & 2 & 3 & 1 & 3.47 & 3.283 & -10.80 & -10.32 \\
\hline 7 & 3 & 1 & 3 & 0.935 & 0.584 & 0.5837 & 4.671 \\
\hline 8 & 3 & 2 & 1 & 1.788 & 1.648 & -5.047 & -4.339 \\
\hline 9 & 3 & 3 & 2 & 3.413 & 3.204 & -10.66 & -10.1 \\
\hline
\end{tabular}

\section{RESULTS \& DISCUSSIONS}

\subsection{Signal to noise ratio}

Genichi Taguchi proposed the theory of signal to noise ratio for robust design, it is considered as one of the appropriate optimization tool to state the quality of the product as per the response to noise ratio at stated signal factor. The signal to noise ratio tool is divided under three sub stages as per the optimization required. They are classified as "smaller the better", "higher the better" and nominal the best". Parameter such as surface roughness, temperature evolved, cutting forces and tool wear are processed under "smaller the better" [10] signal to noise ratio. The $\mathrm{S} / \mathrm{N}$ ratio performed in the present work is executed based on the smaller the better for surface roughness using the equation 1.

$$
\frac{S}{N}=-10 \log _{10}\left(\frac{1}{n} \sum_{i=1}^{n} a_{i}{ }^{2}\right)
$$

Where $\mathrm{S} / \mathrm{N}$ denotes signal to noise ratio.

$\mathrm{Sb}$ denotes smaller the better condition.

$\mathrm{n}$ denotes number to tests.

$\mathrm{a}_{\mathrm{i}}$ denotes the surface roughness values.

Table 5. S/N Response table for surface roughness at dry condition

\begin{tabular}{|l|r|r|r|}
\hline Level & Speed & Feed & Depth of cut \\
\hline 1 & -6.381 & $\mathbf{- 0 . 0 3 2}$ & $\mathbf{- 5 . 3 7 0}$ \\
\hline 2 & -6.375 & -6.881 & -6.262 \\
\hline 3 & $\mathbf{- 5 . 0 4 2}$ & -10.885 & -6.166 \\
\hline Delta & 1.339 & 10.852 & 0.892 \\
\hline Rank & 2 & 1 & 3 \\
\hline
\end{tabular}




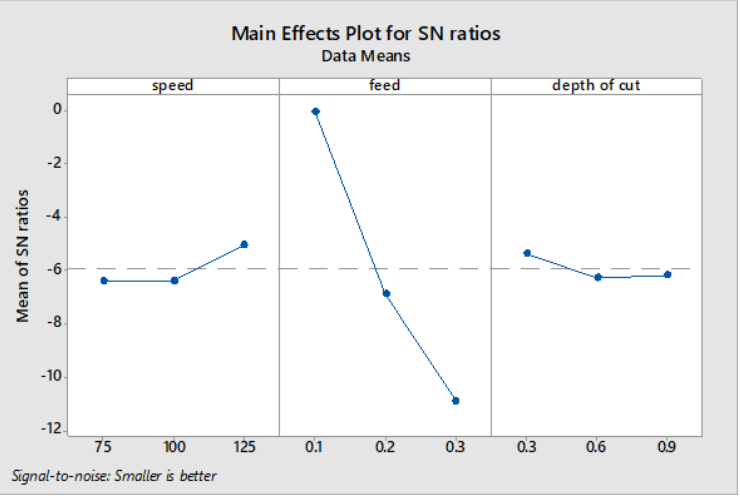

Fig 2. Main effect plots for $\mathrm{S} / \mathrm{N}$ ratio of surface roughness at dry

The mean response of the each parameter corresponding to that level has been calculated in shown in Table 5 for dry turning and Table 6 for MQL Turning.

Table 6. S/N Response table for surface roughness at MQL condition

\begin{tabular}{|l|r|r|r|}
\hline Level & speed & feed & Depth of cut \\
\hline 1 & -4.552 & $\mathbf{4 . 3 4 1}$ & $\mathbf{- 3 . 6 7 2}$ \\
\hline 2 & -3.992 & -5.714 & -3.954 \\
\hline 3 & $\mathbf{- 3 . 2 6 0}$ & -10.432 & -4.179 \\
\hline Delta & 1.292 & 14.773 & 0.507 \\
\hline Rank & 2 & 1 & 3 \\
\hline
\end{tabular}

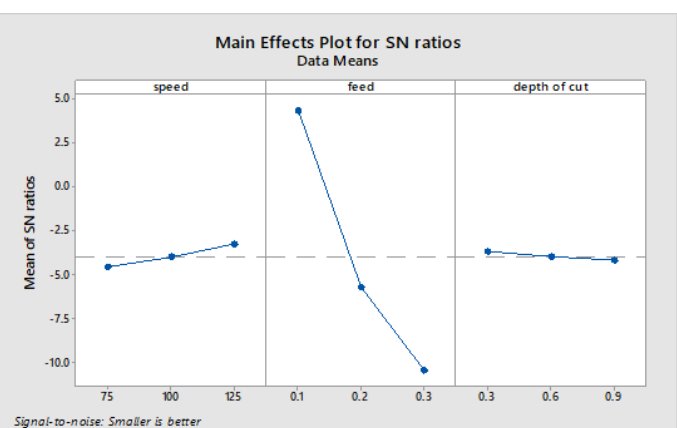

Fig 3. Main effect plots for $\mathrm{S} / \mathrm{N}$ ratio of surface roughness at MQL

From the Table 5 and 6 response table and Fig 2 and 3 of main effect plot it is clear that optimum condition for turning EN45 with uncoated tool under dry and MQL condition was found to be speed at level $3(125 \mathrm{~m} / \mathrm{min})$, feed at level $1(0.1 \mathrm{~mm} / \mathrm{rev})$ and depth of cut at level $1(0.3 \mathrm{~mm})$.

\subsection{Development of mathematical model with regression analysis}

Mathematical regression model was been generated with confidence level of $95 \%$ for surface roughness values obtained from the experimentation in both the cases of ie., under Dry and MQL condition in MINITAB 18. For both the cases the R-Sq and R-Sq(ad) are reported. In the present case for both the regression equations 2 and 3 and their model for dry and MQL are closer to $100 \%$ therefore one can tell that these models having better regression fit.
Dry $\mathrm{Ra}=0.907-0.02246$ speed +8.58 feed +2.11 depth of cut +0.0719 speed*feed -0.00269 speed*depth of cut - 5.64 feed*depth of cut

(2)

$$
\text { R-sq }=99.92 \%, \text { R-sq(adj })=99.68 \%
$$

MQL Ra $=0.0027-0.01200$ speed +13.564 feed +0.086 depth of cut +0.01131 speed*feed +0.00571 speed $*$ depth of cut - 1.486 feed*depth of cut $^{*}$

(3)

$$
\text { R-sq }=99.98 \%, \text { R-sq(adj) }=99.73 \%
$$

\subsection{Analysis of variance}

The analysis of variance states which parameter is most influencing process parameter for an outcome [11]. In the present study machining parameters like speed, feed, depth of cut on received output factors like surface roughness are considered in both the case of turning.

Table 7. ANOVA analysis for surface roughness at dry condition

\begin{tabular}{|l|c|c|c|c|c|c|}
\hline Source & DF & Adj SS & $\begin{array}{c}\text { Adj } \\
\text { MS }\end{array}$ & $\begin{array}{c}\text { F- } \\
\text { Value }\end{array}$ & $\begin{array}{c}\text { P- } \\
\text { Value }\end{array}$ & ocont \\
\hline Regression & 6 & 9.679 & 1.613 & 409.96 & 0.002 & \\
\hline speed & 1 & 0.118 & 0.118 & 30.03 & 0.032 & 41.84 \\
\hline feed & 1 & 0.077 & 0.077 & 19.65 & 0.047 & 27.30 \\
\hline depth of cut & 1 & 0.013 & 0.013 & 3.40 & 0.207 & 4.61 \\
\hline speed*feed & 1 & 0.037 & 0.037 & 9.57 & 0.090 & 13.12 \\
\hline speed*depth of cut & 1 & 0.001 & 0.001 & 0.12 & 0.762 & 0.35 \\
\hline feed*depth of cut & 1 & 0.033 & 0.033 & 8.48 & 0.100 & 11.70 \\
\hline Error & 2 & 0.007 & 0.003 & & & 1.06 \\
\hline Total & 8 & 9.687 & & & & 100 \\
\hline
\end{tabular}

From table 7 it is clear that speed was found to be most influential process parameter that is by $41.84 \%$ for surface roughness when turning En45 material with uncoated tools. And from table 8 it is clear that feed was found to be most influential process parameter that is by $82.83 \%$ for surface roughness when turning En45 material with uncoated tools.

Table 8. S/N Response table for surface roughness at MQL condition

\begin{tabular}{|l|c|c|c|c|c|c|}
\hline & & & Adj & F- & P- & \\
Source & DF & Adj SS & MS & Value & Value & Cont \\
\hline Regression & 6 & 11.25 & 1.876 & 666.4 & 0.000 & \\
\hline speed & 1 & 0.033 & 0.033 & 137.79 & 0.007 & 4.16 \\
\hline feed & 1 & 0.193 & 0.193 & 789.24 & 0.001 & 2.83 \\
\hline depth of cut & 1 & 0.001 & 0.001 & 0.09 & 0.792 & .43 \\
\hline speed*feed & 1 & 0.001 & 0.001 & 3.81 & 0.190 & 0.43 \\
\hline
\end{tabular}




\begin{tabular}{|l|l|l|l|l|l|l|}
\hline $\begin{array}{c}\text { speed*depth of } \\
\text { cut }\end{array}$ & 1 & 0.002 & 0.002 & 8.75 & 0.098 & .86 \\
\hline $\begin{array}{c}\text { feed*depth of } \\
\text { cut }\end{array}$ & 1 & 0.002 & 0.002 & 9.47 & 0.091 & 0.86 \\
\hline Error & 2 & 0.001 & 0.001 & & & 0.43 \\
\hline Total & 8 & 11.26 & & & & 100 \\
\hline
\end{tabular}

\section{Conclusion}

Present paper deals with the Taguchi optimization of surface roughness values evolved during turning of EN45 steel under dry and MQL conditions. As stated, The following are the conclusions detailed from the work.

1. MQL proved to be more effective in reducing surface roughness evolved during the turning operation.

2. The optimum conditions for surface roughness for both dry turning and MQL was cutting speed at level $3(125 \mathrm{~m} / \mathrm{min})$, feed at level $1(0.1$ $\mathrm{mm} / \mathrm{rev})$ and depth of cut at level $1(0.3 \mathrm{~mm})$.

3. Speed was found to be the most contributing parameter by $41.84 \%$ for surface roughness value in case of dry through ANOVA analysis

4. Feed was found to be most contributing parameter $82.83 \%$ for surface roughness value in case of MQL turning through ANOVA analysis

\section{Reference}

1. Boswell, B., Islam, M. N., Davies, I. J., Ginting, Y. R., \& Ong, A. K. INT J ADV MANUF TECH 92(14), 321-340 (2017)

2. Sharma, V. S., Dogra, M., \& Suri, N. M. Int. J. Mach, 49(6), 435-453 (2009)

3. Nouioua, M., Yallese, M. A., Khettabi, R., Belhadi, S., Bouhalais, M. L., \& Girardin, F. INT J ADV MANUF TE9CH, 93(5-8), 2485-2504 (2017)

4. Jegatheesan, V., Liow, J. L., Shu, L., Kim, S. H., \& Visvanathan, C. J. Clean. Prod, 17(7), 637-643 (2009)

5. Sadeghi, M. H., Haddad, M. J., Tawakoli, T., \& Emami, M. INT J ADV MANUF TECH, 44(5), 487-500 (2009)

6. Gaitonde, V. N., et al. Mater. Manuf. Process, 24(12) 1373-1382 (2009)

7. Satyanarayana, Kosaraju, Anne Venu Gopal, and Popuri Bangaru Babu., ijmmm. 13(2-3), 191-202. (2013)

8. Srinivasa Rao D, Sandhya Rani MN, Sarfaraz Naw az Syed and Suresh Kumar Tummala, E3S Web of Conferences 8701003 (2019).

9. Athreya, S., \& Venkatesh, Y. D. Int. J. Eng. Sci, 1(3), 13-19 (2012)

10. Günay, M., \& Yücel, E. MEASUREMENT 46(2), 913-919 (2013)

11. Satyanarayana Kosaraju and Chandraker, Satyam. Materials Today: Proceedings 2.4 (2015): 33883393, (2015) 